\title{
Manifestation of Psychological Disorders in Medico-Legal Cases
}

\author{
Saima Majeed* \\ Punjab Institute of Mental Health, Lahore, Pakistan \\ Email: saimamajeed57@yahoo.com, saimapsychologistpimh@gmail.com
}

How to cite this paper: Majeed, S. (2020). Manifestation of Psychological Disorders in Medico-Legal Cases. Psychology, 11, 9931004.

https://doi.org/10.4236/psych.2020.117064

Received: April 7, 2020

Accepted: July 13, 2020

Published: July 16, 2020

Copyright $\odot 2020$ by author(s) and Scientific Research Publishing Inc. This work is licensed under the Creative Commons Attribution International License (CC BY 4.0).

http://creativecommons.org/licenses/by/4.0/

\begin{abstract}
The relationship between mental illnesses and criminal behavior is a topic of debate for last many years. It is a popular thinking that people with mental illnesses are more vulnerable towards aggression, violence, and other criminal acts. The aim of the present study was to examine the manifestation of psychological disorders in cases referred to Punjab Institute of Mental Health (PIMH), Lahore Pakistan for forensic psychological assessment. The archival data from the year 2017 to 2019 of cases was obtained from patient clerk of PIMH. Results indicated that total cases that reported were 174 . More men ( $f=145,83.3 \%)$ were reported for forensic assessment as compared to women $(f=29,16.7 \%)$. As far as residential area was concerned more cases came from urban areas $(f=94,54 \%)$ as compared to rural areas $(f=80,46 \%)$. The most reported criminal act was a threat to harm and murder. The aggression and murder cases were more reported from rural background. Intellectual disability $(f=56,32.2 \%)$ and schizophrenia $(f=51$, $29.3 \%)$ was the highest reported diagnosis. Intellectual disability was reported more from urban background whereas schizophrenia reported more from rural background. Chi-square results showed significant relationship between criminal acts and psychiatric illnesses, significant relationship between gender and criminal behavior as well as psychological illness was also found. Likewise, analysis of residential areas showed the difference between urban and rural areas regarding illness as well as criminal acts. The important implication of the present research was in the field of forensic psychology and legal system.
\end{abstract}

\section{Keywords}

Medico-Legal Cases, Forensic Assessment, Psychiatric Disorder, Criminal Behaviour 


\section{Introduction}

The aim of the present study was to examine the manifestation of Psychological disorders in cases referred to Punjab Institute of Mental Health (PIMH) for forensic psychological assessment. PIMH is a mega institute of Punjab, Pakistan dealing with assessment and treatment of all psychiatric disorders on outdoor basis as well as catering 1510 in patients. Forensic psychological assessment of the individuals who appeal for not fit for trial due to mental illness is also conducted in PIMH by a medical board comprised of Psychiatrists, clinical Psychologists, and other medical professionals.

The phenomenon of forensic psychology is although not very new in Pakistan, but research evidence is really very scarce in this field of psychological assessment. Keeping in mind the importance of proved guilty or not guilty based on insanity the role of psychiatrists and clinical psychologist in the assessment of criminal offenders is extremely sensitive. It is a need of the hour to spread awareness regarding the prevalence of psychiatric illness in those people who caught by police personals with accused of any crime.

Schizophrenia is a major mental illness in which individuals cannot foresee the impacts of their behavior. They live in an unreal world of beliefs and sensory experiences which has no relationship with the real world. Whereas Pakistan supreme court passed a verdict against 50 years old male diagnosed by psychiatrists after 8 years of treatment with paranoid schizophrenia who was symptom free at the time of the hearing in court, so thinking that schizophrenia is a treatable disorder. According to honorable supreme court, schizophrenia is not a permanent mental disorder so that person proved guilty. This decision was faced with a backlash not only by mental health professionals but also by the human rights organizations. This incident also raises the importance of working together with the law enforcement agencies and mental health professionals especially in making decisions for the arrest, charged and jail to the people involved in criminal acts but also having mental disorders. "Guilty but mentally ill" is added in the USA legal system for insanity plea to permit the legal system to assess the intent and state of mind of the person at the time of the crime and also monitor for admissions of the patients who need psychological treatment rather just confinement (Melamed, 2010).

The relationship between mental illnesses and criminal behavior is a topic of debate for last many years. It is a popular thinking that people with mental illnesses are more vulnerable towards aggression, violence and other criminal acts. This stigma may increase due to the media representation of people with psychiatric illness as "crazy" (Stout, Villegas, \& Jennings, 2004). It is also a public perception that dangerousness and mental illness are interwoven and most of aggressive acts like mass shooting are done by people with mental illnesses. This misconception further enhances to the concealment of psychiatric diagnosis and not seeking for psychological help (Varshney et al., 2016).

Whereas a plethora of research is also evidence of a different point of view and that is the people with mental illnesses are the victims of aggression and vi- 
olence far more than public (Lamberti et al., 2001). Many psychological symptoms including impaired reality testing, impulsivity, lack of insight and judgment, poor problem-solving skills can make persons more vulnerable to physical and psychological assault (Newman et al., 2010; Sells et al., 2003). Violent victimization of people with mental illnesses done by primary care givers, attendants at hospital facility and by public in general. This type of victimization is not highlighted as compared to violent acts by patients of psychological disorders. Although research proved that victimization of mentally ill people is outnumbered as compared to violent acts by them (Maniglio, 2009; Choe, Templin, \& Abram, 2008; Brekke et al., 2001). There is increase number of evidence that people with intellectual disability are the victims or witness of crime. Some of the individuals living in such an area where crimes are common and they become the target of offenders for victimization (Kebbell \& Davies, 2003). Research in the field of forensic psychology reported many ccriminological variables who had superior predictive efficacy over clinical variables with respect to recidivism in Intellectual disability and mentally disordered offenders (Bonta, Law, \& Hanson, 1998).

The basic rationale of present study was to high light the importance of forensic assessment of those individuals who committed any illegal act but also showing some of the symptoms of mental illnesses. These peoples are arrested and charged in the same way as other criminal and even in some cases jailed for more years as compare to the general population. This is the need of the hour to differentiate between criminals and people who commit illegal acts due to their mental illness. They are not aware of the consequences of their acts neither plan nor foresee the impacts of their behaviors. There is also a lifetime risk for people suffering from psychiatric illnesses that engage in any criminal behavior (Swanson \& Belden, 2018). So again, it is essential to diagnose people with mental illness so that their treatment can be done to reduce the risk for criminality.

With the passage of time, it has been acknowledge in the western world that therapeutic justice system is required to deal with psychosocial issues like addiction, mental illnesses and domestic violence which is associated with criminal behavior and reoffending (Winick, 2002). Present research was also initiated with the idea that traditional justice system is not sufficient to deal with people who are involved in some illegal acts but at the same time also suffering from any mental disorders. The results of this study will high light the importance of problem solving which is an important part of therapeutic justice system to detect and eliminate the origin of such problems.

\section{Objective of the Study}

To examine the manifestation of Psychological disorders in cases referred by courts for forensic psychological assessment.

$>$ To determine the association between psychological disorders and criminal behaviours.

$>$ To determine the relationship between demographic profile and criminal behavior. 


\section{Method}

\subsection{Research Design}

The present research is a retrospective study with descriptive research design.

\subsection{Participants}

The archival data was approached of cases referred for forensic psychological assessment to PIMH during the calendar year of 2017-2019.

\section{Inclusion/Exclusion Criteria}

All cases completed with psychological medical board in between the years of 2017-2019. The cases referred for guardianship were not included for present study.

\subsection{Measures}

Archival data was used for the purpose of collecting the required information according to the objective of the present research with the help of demographic information sheet and psychiatric history Performa.

\subsection{Ethical Considerations}

Following ethical issues were considered during the research study.

- Data collection was initiated after the approval of Institutional Review Board of PIMH.

- Permission for data collection was taken from Executive Director of PIMH.

- No identification information was expressed, and anonymity of the participants was also safe guarded.

- Data would remain confidential and would only be used for research purpose.

\subsection{Procedure}

Permission for data collection was taken from the Executive director of Punjab Institute of Mantel Health (PIMH). Record of Medico Legal cases was obtained from Patient Clerk of PIMH during the year of 2017-2019. Only research objective related information was collected. Collected information would remain confidential and would be used only for research purpose.

\section{Results}

The cases which referred for the medical fitness certificate or guardianship for early retirement purposes were excluded from the final data analyses. Descriptive analysis was used for demographic questionnaire and to see the manifestation of Psychiatric Disorders. Chi-square was used to investigate the association between psychiatric disorders and criminal offenses. Statistical Package for Social Science version 21 (SPSS) was used for all analyses.

Results indicated that total cases that reported were 174. More men $(f=145$, 
83.3\%) were reported for forensic assessment as compared to women $(f=29$, $16.7 \%)$. As far as residential area is concerned more cases come from urban area $(f=94,54 \%)$ as compared to rural areas $(f=80,46 \%)$.

The results in Table 1 indicated that most of the people sent for forensic assessment were convicted with murder and showing aggression to others. The psychological disorder that involves in theses crime was schizophrenia and people with intellectual disability was also involved in aggressive behavior.

Table 2 indicated the gender role in psychiatric disorders. As men are already outnumbered so they also fall more in each category of the disorder. The highest diagnosis made is schizophrenia and intellectual disability. Chi-square results show that there is a significant relationship between gender and psychiatric illness $\left(X^{2}=10.21, p=0.25\right)$.

Table 3 indicated gender role in criminal behavior. Women fall in each category except rape and attempt to murder. But five women also charged in 302 that is murder offence. Chi-square results show that there is a significant relationship between gender and criminal acts $\left(X^{2}=5.81, p=0.44\right)$.

Results of Table 4 show that total 6 individuals were screened with no psychological disorder 3 each from urban and rural residential background. More individuals from urban background diagnosed with intellectual disability and schizophrenia was diagnosed more in people coming from rural background. Chi-square results show that there is a significant relationship between residential area and psychiatric illness $\left(X^{2}=10.21, p=0.25\right)$.

Table 5 indicated the charges of aggression and theft were deployed more on people living in urban areas more as compared to rural areas. Whereas section 295 (injuring/defiling others religion) reported more from rural areas. Chisquare results show that there is a significant relationship between residential area and criminal acts $\left(X^{2}=27.58, p=0.00\right)$.

Table 1. Manifestation of psychological disorders in participants $(\mathrm{N}=174)$ with reference to their criminal acts.

\begin{tabular}{|c|c|c|c|c|c|c|c|}
\hline & Aggression & Theft & $\begin{array}{l}\text { Attempt to } \\
\text { Murder }\end{array}$ & $\begin{array}{c}\text { Injuring or } \\
\text { Defiling Other's } \\
\text { Religion }\end{array}$ & Murder & Kidnapping & Rape \\
\hline $\begin{array}{l}\text { No Psychiatric } \\
\text { Illness }\end{array}$ & 5 & 0 & 0 & 0 & 1 & 0 & 0 \\
\hline Schizophrenia & 21 & 4 & 1 & 7 & 14 & 2 & 2 \\
\hline $\begin{array}{l}\text { Intellectual } \\
\text { Disability }\end{array}$ & 25 & 27 & 1 & 3 & 1 & 0 & 0 \\
\hline $\begin{array}{l}\text { Bipolar } \\
\text { Disorder }\end{array}$ & 14 & 2 & 1 & 5 & 7 & 2 & 0 \\
\hline $\begin{array}{l}\text { Organic Brian } \\
\text { Syndrome }\end{array}$ & 9 & 5 & 0 & 0 & 0 & 0 & 0 \\
\hline MDD & 5 & 0 & 0 & 0 & 0 & 0 & 0 \\
\hline $\begin{array}{c}\text { Schizoaffective } \\
\text { Disorder }\end{array}$ & 4 & 2 & 0 & 1 & 0 & 0 & 0 \\
\hline
\end{tabular}


Table 2. Gender based association for psychiatric illness.

\begin{tabular}{ccc}
\hline Psychiatric illnesses & Men $(\boldsymbol{n}=\mathbf{1 4 5}) \boldsymbol{f}$ & Women $(\boldsymbol{n}=\mathbf{2 9}) \boldsymbol{f}$ \\
\hline No Psychiatric Illness & 5 & 1 \\
Schizophrenia & 44 & 7 \\
Mental Retardation & 46 & 11 \\
Bipolar disorder & 16 & 8 \\
Organic Brain Syndrome & 13 & 1 \\
MDD & 5 & 0 \\
Dementia & 8 & 0 \\
Schizoaffective Disorder & 2 & 1 \\
Epilepsy & 4 & 0 \\
\hline
\end{tabular}

Table 3. Gender based association for criminal acts.

\begin{tabular}{ccc}
\hline Criminal Acts & Men $(\boldsymbol{n}=\mathbf{1 4 5}) \boldsymbol{f}$ & Women $(\boldsymbol{n}=\mathbf{2 9}) \boldsymbol{f}$ \\
\hline Threat & 71 & 13 \\
Theft & 31 & 9 \\
Attempt to Murder & 3 & 0 \\
Injuring or defiling others religion & 15 & 5 \\
Murder & 19 & 1 \\
Kidnapping & 5 & 0 \\
Rape & 1 & \\
\hline
\end{tabular}

Table 4. Residential based association for psychiatric illness.

\begin{tabular}{ccc}
\hline Psychiatric Illness & Urban $(\mathrm{n}=\mathbf{9 3}) \boldsymbol{f}$ & Rural $(\mathrm{n}=\mathbf{8 0}) \boldsymbol{f}$ \\
\hline No Psychiatric Illness & 3 & 3 \\
schizophrenia & 22 & 29 \\
Mental retardation & 41 & 16 \\
Bipolar Disorder & 8 & 16 \\
Organic Brain Syndrome & 8 & 6 \\
MDD & 3 & 2 \\
Dementia & 6 & 2 \\
Schizoaffective Disorder & 2 & 1 \\
Epilepsy & 1 & 3 \\
\hline
\end{tabular}

Table 5. Residential based criminal acts.

\begin{tabular}{ccc}
\hline Criminal Acts & Urban $(\mathrm{n}=\mathbf{9 3}) \boldsymbol{f}$ & Rural $(\mathrm{n}=\mathbf{8 0}) \boldsymbol{f}$ \\
\hline Threat/Aggression & 46 & 38 \\
Theft & 32 & 8 \\
Attempt to Murder & 3 & 0 \\
Injuring/Defiling others Religion & 4 & 12 \\
Murder & 7 & 17 \\
Kidnapping & 2 & 3 \\
Rape & 0 & 2 \\
\hline
\end{tabular}


According to Figure 1, the most reported criminal act for which individuals were charged by the police was showing aggression towards people in the form of physical fights, throwing things and being abusive. The second major offense reported was murder.

Figure 2 depicted that the most reported psychological disorder was Schizophrenia and Intellectual disability (Mental retardation) for present population of the study.

\section{Discussion}

Forensic assessment of the people who did any criminal act and suffering from mental disorders carries a lot of burden on the part of psychiatrists and clinical psychologists involved in their assessment. Results from the review of the data from the year 2017 to 2019 reported in PIMH for forensic assessment revealed many important aspects. First the role of gender, that is more men were reported for medico legal assessment as compared to women. Many speculations can be inferred from this trend. First, the women who suffered from mental disorders are less involved in criminal acts. Secondly being a collectivistic culture and sensitive towards women respect the responsibility of crime may shift towards men. Legal system may sometime highlight the crime and mental illness of men more than women. Men are more involved in aggressive tendencies than women. Shafqat, Majeed, and Malik (2019) studied the aggressive and sadistic impulsive tendencies in prisoners of Lahore, Pakistan. They concluded that more men were involved in aggression while women score higher on sadistic impulsiveness. According to Vogel and Messner (2012), it is not the mental disorder that elicits criminal behavior but the many criminogenic risk factor that can complex the interplay of mental disorders and criminal behavior.

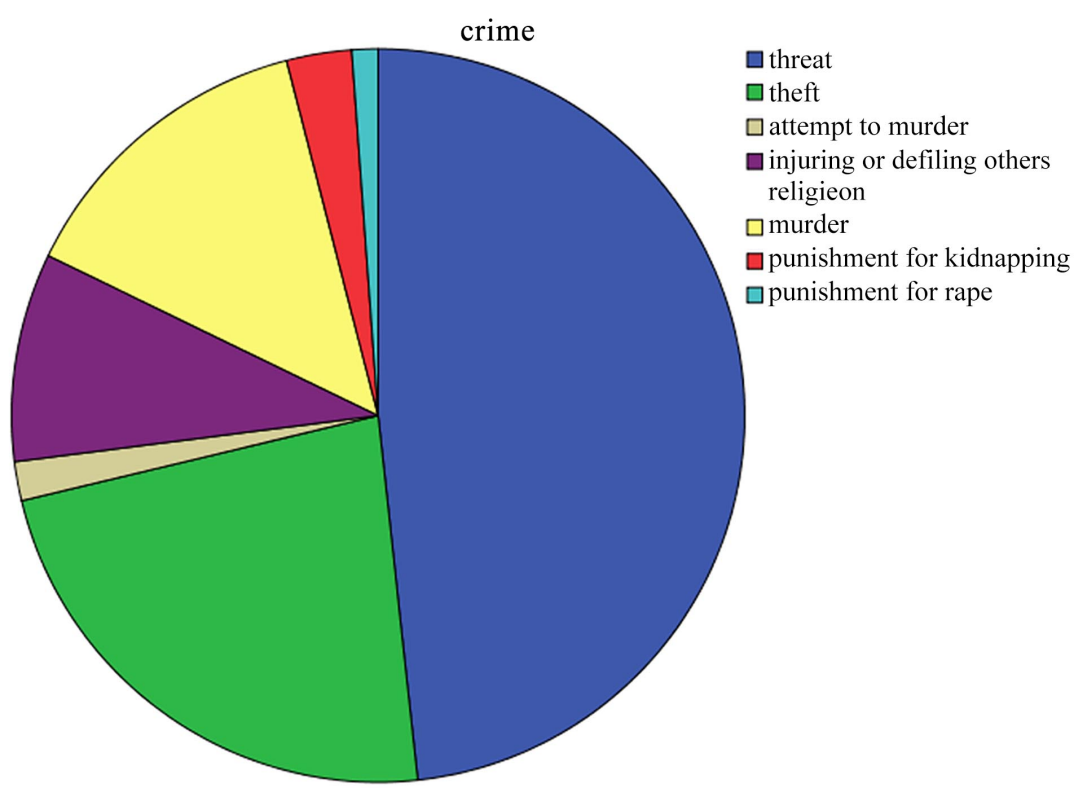

Figure 1. Pie chart of Crime reported $(\mathrm{N}=174)$. 


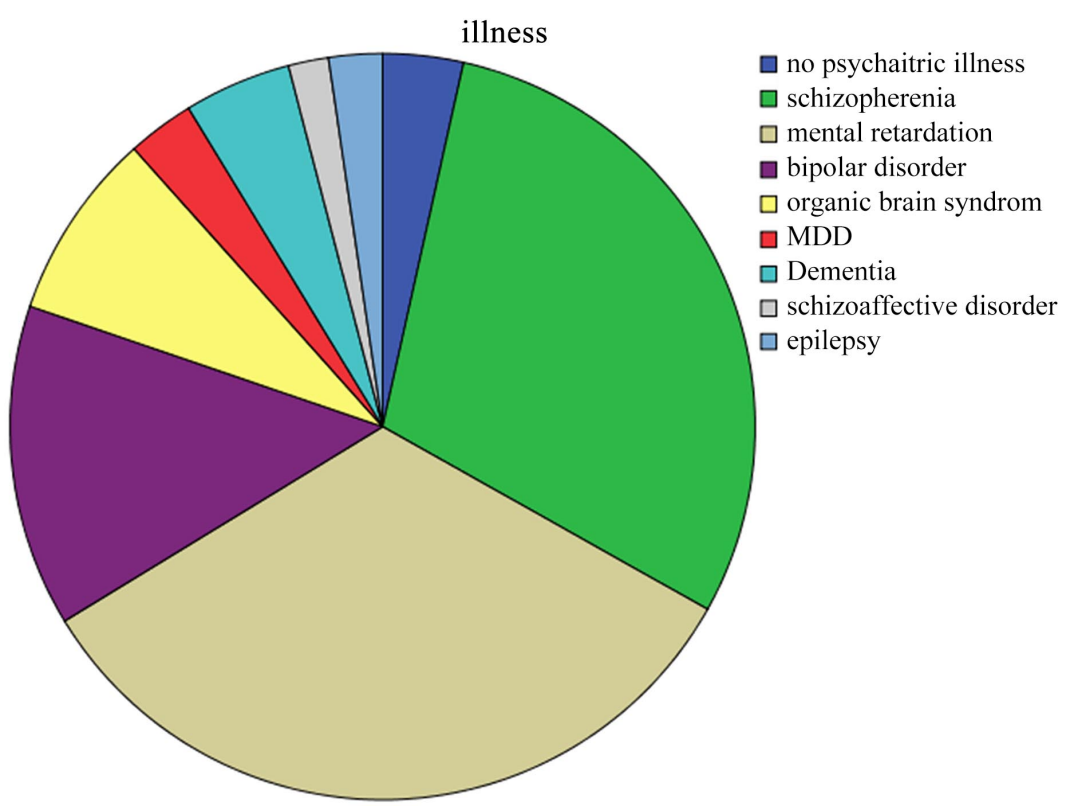

Figure 2. Pie chart of psychological disorders reported $(\mathrm{N}=174)$.

The most common diagnosis that made was intellectual disability. People with intellectual disability are lacking with cognitive and adaptive skills. Their IQ is less than 70 and they also lacking critical, abstract and analytic thinking. In many cases they were not even aware of the consequences of their behavior, so recidivism is very common in people with intellectual disability (Klimecki, Jenkinson, \& Wilson, 2009). Holland and Persson (2011) stated that although the prevalence of people with ID involved in crime was not outnumbered but they are different in many aspects. The salient features were prior involvement in criminal behavior, recidivism, problems with minimum security in jails and in obtaining parole. They further added that prisoners with ID are a group with multifaceted pasts and needs, which can present a substantial challenge to the criminal as well as to the rehabilitation system. The research is also neither sufficient nor conclusive with respect to the risk factors involved in reoffending of people with intellectual disability when compared with general population of criminals, where psychological, social and forensic factors are well established (Fitzgerald, Gray, Taylor, \& Snowden, 2011).

The present study results indicated that second most prevalent diagnosis was schizophrenia. According to Kamau (2016), schizophrenia is considered as incurable psychiatric disorder. People suffering from schizophrenia must not be considered as deliberate criminals however government should provide facilities for their treatment. For public safety, their confinement is also particularly important but with the aim of their treatment. Likewise, Vogel and Messner (2012) stated that people with psychotic disorders and other externalizing problems were more engage in violence than with other types of mental disorders. Furthermore, Volavka and Citrome (2011) suggested that there is risk for criminal acts if person is suffering from certain mental illness. People with active delu- 
sions and command hallucination or long-term paranoia comorbidity with substance use disorders are more prone towards criminal behavior (Walsh, Buchman, \& Fahy, 2002).

Present study results also highlighted that people suffering from bipolar disorder also involved in criminal acts. Hodgins (1992) reported that there is lifetime prevalence rate of prisoners for the diagnosis of MDD who commit the homicide. Some researchers also talked about interplay of many factors like unemployment, homelessness, cognitive impairment, and brain damage due to any illness (Köşger et al., 2016). The prevalence of mental illnesses is much higher in people who encounter criminal justice system as compared to the general population (Teplin et al., 2002). In another literature review, Fazel and Danseh (2002) reported that psychosis, major depression, and antisocial personality disorder is common in adult prison inmates. The occurrence of Behaviour Disruptive Disorder including Oppositional defiant disorder and conduct disorder is higher in juvenile offenders as compared with the general population.

Chi-square results indicated that men and women were different regarding their criminal acts as well as psychiatric illnesses. Difference detected in urban rural background as more murder cases reported from rural background and showing aggression cases was more reported in urban background. Furthermore, schizophrenia is more reported in cases from rural background and intellectual disability is more reported from urban background.

The link between psychological disorders and criminal behavior is not a linear one. Many research evidences fail to detect its simple relationship, so it can be inferred that there must be many mediators and moderators. It carries many ifs and buts and interplay of many factors including psychological and social. So further research should consider its psychosocial correlates for some conclusive results.

\section{Implications and Future Directions}

A very important implication of the present study is to highlight a sensitive issue of committing the offenses whether it is under section 302 "murder" or under section 295 that is "injuring or defiling place of worship, with intent to insult the religion of any class" by people with mental disorders. In PIMH many cases with this section diagnosed with schizophrenia or intellectual disability. Instead of keeping them into jail or finning them, their psychological intervention is recommended. In a larger perspective, our forensic services and disability service systems should merge their facilities for such individuals to the betterment of society as well as to these individuals. A multidisciplinary team including psychiatrist, clinical psychologists/forensic psychologists, social worker and patient advocates could be deputed to fill the gaps between detection and then treatment of people with mental disorders before they commit any crime. Mental Health Ordinance of Pakistan 2001 and Sindh Mental Health act 2013 should be revisited with the perspective of the rights of people who are suffering from mental 
illnesses and also involved in any illegal act. The awareness regarding rights of the people with mental disorders should be the priority of mental health legislations. It will also reduce the misconceptions of the individuals with mental disorders are more involved in criminal acts then a general population as well as to safeguard their rights.

\section{Acknowledgements}

The author acknowledges the support that hospital authorities provided for data collection. No financial grant received for this study.

\section{Funding}

It was a non-funded research study. Author did not receive any benefits from institution or elsewhere to carry out present research.

\section{Author's Contribution}

Dr. Saima Majeed conceived the idea of present study. She collected the data, analyzed it and drew conclusions. Manuscript was prepared by Dr. Saima Majeed and reviewed it before final submission.

\section{Conflicts of Interest}

The author declares no conflicts of interest regarding the publication of this paper.

\section{References}

Bonta, J., Law, M., \& Hanson, K. (1998). The Prediction of Criminal and Violent Recidivism among Mentally Disordered Offenders: A Meta-Analysis. Psychological Bulletin, 123, 123-142. https://doi.org/10.1037/0033-2909.123.2.123

Brekke, J. S., Prindle, C., Bae, S. W., \& Long, J. D. (2001). Risks for Individuals with Schizophrenia Who Are Living in the Community. Psychiatric Services, 52, 1358-1366. https://doi.org/10.1176/appi.ps.52.10.1358

Choe, J. Y., Teplin, L. A., \& Abram, K. M. (2008). Perpetration of Violence, Violent Victimization, and Severe Mental Illness: Balancing Public Health Concerns. Psychiatric Services, 59, 153-164. https://doi.org/10.1176/ps.2008.59.2.153

Fazel, S., \& Danesh, J. (2002). Serious Mental Disorder in 23000 Prisoners: A Systematic Review of 62 Surveys. The Lancet, 359, 545-550. https://doi.org/10.1016/S0140-6736(02)07740-1

Fitzgerald, S., Gray, N. S., Taylor, J \& Snowden, R. J. (2011). Risk Factors for Recidivism in Offenders with Intellectual Disabilities. Psychology, Crime \& Law, 17, 43-58. https://doi.org/10.1080/10683160903392293

Hodgins, S. (1992). Mental Disorder, Intellectual Deficiency, and Crime: Evidence from a Birth Cohort. Archives of General Psychiatry, 49, 476-483. https://doi.org/10.1001/archpsyc.1992.01820060056009

Holland, S., \& Persson, P. (2011). Intellectual Disability in the Victorian Prison System: Characteristics of Prisoners with an Intellectual Disability Released from Prison in 2003-2006. Psychology, Crime \& Law, 17, 25-41. 
https://doi.org/10.1080/10683160903392285

Kamau, C. (2016). Is the NHS Mental Health Service Preparing Clients to Resume Employment? Psychiatric Services, 67, 578-579. https://doi.org/10.1176/appi.ps.201600008

Kebbell, M., \& Davies, G. (2003). People with Intellectual Disabilities in the Investigation and Prosecution of Crime. Legal and Criminological Psychology, 8, 219-222. https://doi.org/10.1348/135532503322362988

Klimecki, M. R., Jenkinson, J., \& Wilson, L. (2009). A Study of Recidivism among Offenders with Intellectual Disability. Australia and New Zealand Journal of Developmental Disabilities, 19, 209-219. https://doi.org/10.1080/07263869400035241

Köşger, F., Eşsizoğlu, A., Sönmez, İ., Güleç, G., Genek, M., \& Akarsu, Ö. (2016). The Relationship between Violence and the Clinical Features, Insight and Cognitive Functions of Patients with Schizophrenia. Turkish Journal of Psychiatry, 27.

Lamberti, J. S., Weisman, R. L., Schwarzkopf, S. B., Price, N., Ashton, R. M., \& Trompeter, J. (2001). The Mentally Ill in Jails and Prisons: Towards an Integrated Model of Prevention. Psychiatric Quarterly, 72, 63-77. https://doi.org/10.1023/A:1004862104102

Maniglio, R. (2009). Severe Mental Illness and Criminal Victimization: A Systematic Review. Acta Psychiatrica Scandinavica, 119, 180-191. https://doi.org/10.1111/j.1600-0447.2008.01300.x

Melamed, Y. (2010). Mentally Ill Persons Who Commit Crimes: Punishment or Treatment? The Journal of the American Academy of Psychiatry and the Law, 38, 100-103.

Newman, J. M., Turnbull, A., Berman, B. A., Rodrigues, S., \& Serper, M. R. (2010). Impact of Traumatic and Violent Victimization Experiences in Individuals with Schizophrenia and Schizoaffective Disorder. The Journal of Nervous and Mental Disease, 198, 708-714. https://doi.org/10.1097/NMD.0b013e3181f49bf1

Sells, D. J., Rowe, M., Fisk, D., \& Davidson, L. (2003). Violent Victimization of Persons with Co-Occurring Psychiatric and Substance Use Disorders. Psychiatric Services, 54, 1253-1257. https://doi.org/10.1176/appi.ps.54.9.1253

Shafqat, A., Majeed, S., \& Malik, F. (2019). Sadistic Impulsiveness and Violent Behaviour in Prisoners of Lahore. Pakistan Journal of Criminology, 11, 28-42.

Stout, P. A., Villegas, J., \& Jennings, N. A. (2004). Images of Mental Illness in the Media: Identifying Gaps in the Research. Schizophrenia Bulletin, 30, 543-561. https://doi.org/10.1093/oxfordjournals.schbul.a007099

Swanson, J. W., \& Belden, C. M. (2018). The Link between Mental Illness and Being Subjected to Crime in Denmark vs the United States: How Much Do Poverty and the Safety Net Matter? JAMA Psychiatry, 75, 669-670. https://doi.org/10.1001/jamapsychiatry.2018.0528

Teplin, L. A., Abram, K. M., McClelland, G. M., Dulcan, M. K., \& Mericle, A. A. (2002). Psychiatric Disorders in Youth in Juvenile Detention. Archives of General Psychiatry, 59, 1133-1143. https://doi.org/10.1001/archpsyc.59.12.1133

Varshney, M., Mahapatra, A., Krishnan, V., Gupta, R., \& Deb, K. S. (2016). Violence and Mental Illness: What Is the True Story? Journal of Epidemiology and Community Health, 70, 223-225.

Vogel, M., \& Messner, S. F. (2012). Social Correlates of Delinquency for Youth in Need of Mental Health Services: Examining the Scope Conditions of Criminological Theories. Justice Quarterly, 29, 546-572. https://doi.org/10.1080/07418825.2011.582879

Volavka, J., \& Citrome, L. (2011). Pathways to Aggression in Schizophrenia Affect Results of Treatment. Schizophrenia Bulletin, 37, 921-929.

https://doi.org/10.1093/schbul/sbr041 
Walsh, E., Buchanan, A., \& Fahy, T. (2002). Violence and Schizophrenia: Examining the Evidence. The British Journal of Psychiatry, 180, 490-495.

https://doi.org/10.1192/bjp.180.6.490

Winick, B. J. (2002). Therapeutic Jurisprudence and Problem-Solving Courts. Fordham Urban Law Journal, 30, 1055. 